\title{
HUBUNGAN KEJADIAN STUNTING DENGAN FREKUENSI DAN DURASI PENYAKIT ISPA PADA ANAK USIA TODDLER DI WILAYAH KERJA PUSKESMAS KENJERAN SURABAYA
}

\section{The Relationship Between the Incidence of Stunting and the Frequency and Duration of Acute Respiratory Infection in Toddler in the Working Area of Kenjeran Health Center in Surabaya}

\author{
Diyah Arini ${ }^{1}$, Christina Yuliastuti ${ }^{1}$, Ike Faradilah ${ }^{2 *}$
}

1. Stikes Hangtuah Surabaya

2. Magister Keperawayan Universitas Airlangga

Riwayat artikel:

Diajukan: 11 Agustus 2019

Diterima: 5 July 2020

\section{Penulis Korespondensi: \\ - Ike Faradilah \\ - Magister Keperawatan Universitas Airlangga faradilah06@gmail.com}

\section{Kata Kunci: \\ Kejadian Stunting, Frekuensi, Durasi, Penyakit ISPA}

\begin{abstract}
Abstrak
Pendahuluan : Infeksi Saluran Pernapasan Atas (ISPA) yang berulang menyebabkan kondisi kesehatan anak menurun sehingga berdampak pada pola nafsu makan anak yang dapat menyebabkan status gizi anak kurang. Tujuan: Penelitian ini bertujuan untuk menganalisis hubungan kejadian stunting dengan frekuensi dan durasi ISPA pada anak usia toddler di Wilayah Kerja Puskesmas Kenjeran Surabaya. Metode: Desain penelitian analitik korelasi dengan pendekatan cross sectional pada 4 Kelurahan antara lain Kelurahan Kenjeran, Kelurahan Bulak, Kelurahan Kedung Cowek, dan Kelurahan Sukolilo. Pengambilan data dilakukan dengan lembar kuisioner dan observasi menggunakan microtoise, teknik sampel menggunakan Probability Sampling dengan menggunakan Stratified Random Sampling sebanyak 152 anak. Hasil: Hasil penelitian bahwa anak toddler yang mengalami kejadian stunting dengan frekuensi dan durasi penyakit ISPA menunjukkan anak yang stunting memiliki frekuensi dan durasi lebih lama. Uji Spearmen Rho menunjukkan adanya hubungan kejadian stunting dengan frekuensi ISPA $p=0.001 \quad(\rho=0.05)$, durasi ISPA $p=0.001 \quad(\rho=0.05)$. Kesimpulan: Implikasi penelitian ini adalah kejadian stunting berhubungan dengan frekuensi dan durasi penyakit ISPA, sehingga kegiatan posyandu dapat menambahkan penyuluhan tentang kesehatan anak terutama penanganan pertama penyakit ISPA pada anak toddler di Wilayah Kerja Puskesmas Kenjeran Surabaya.
\end{abstract}

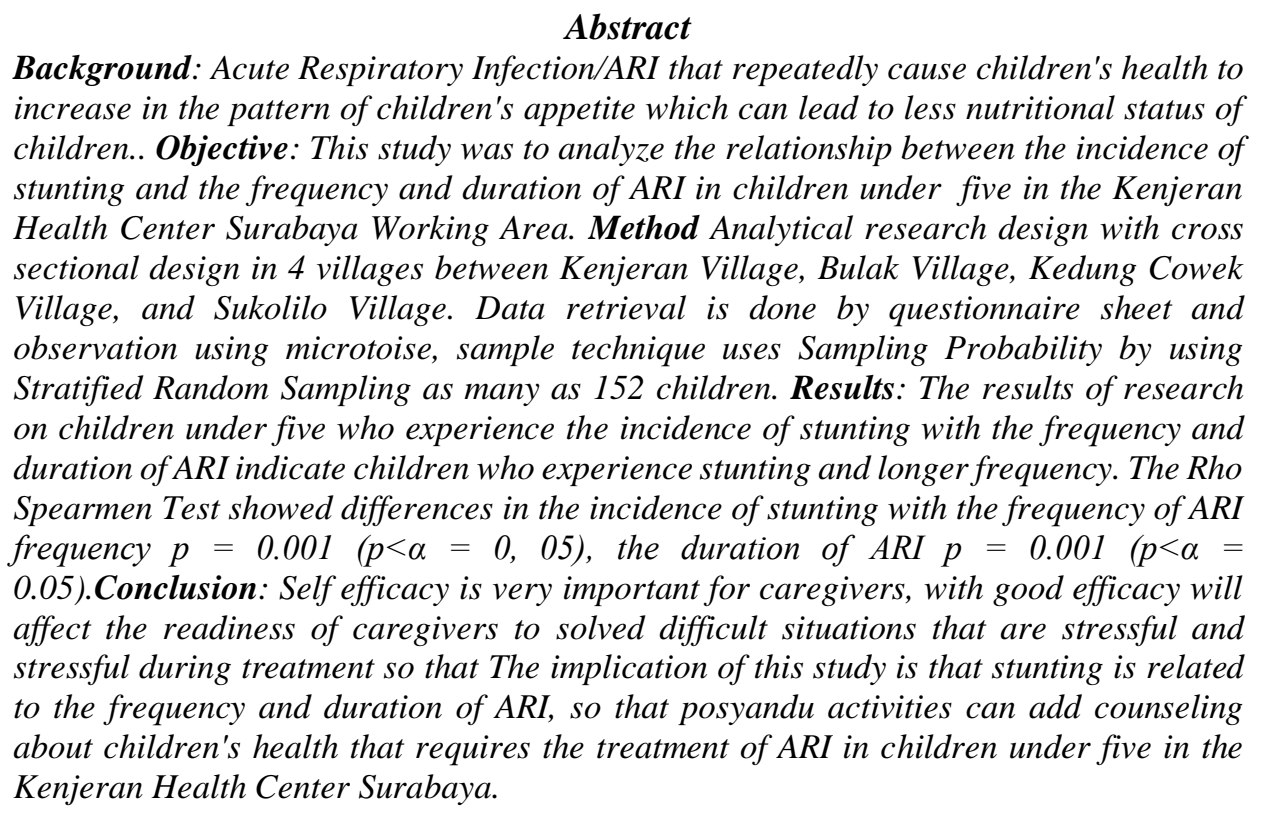




\section{PENDAHULUAN}

Upaya peningkatan status gizi masyarakat termasuk penurunan prevalensi balita pendek menjadi salah satu prioritas pembangunan nasional dengan target penurunan pravelensi menjadi $28 \%$ (Kementrian Kesehatan RI, 2015). Stunting adalah balita dengan status gizi yang berdasarkan panjang atau tinggi badan menurut umurnya dengan nilai z-scorenya kurang dari -2SD dan dikategorikan sangat pendek jika nilai z-scorenya kurang dari (WHO, 2018). Literatur mengungkapkan bahwa anak stunting mengalami serangan infeksi berulang dan lama ISPA pada anak 27 hari per tahun (Alberto et al., 2016) (Anshori, 2013), frekuensi ISPA > 6 kali per episode (Fatmawati, 2018).

Kejadian stunting merupakan salah satu masalah gizi yang dialami oleh balita di dunia saat ini. Pada tahun 2017 22,2\% atau sekitar 162 juta balita di dunia mengalami stunting (States, 2012). Berdasarkan Riset Kesehatan Dasar tahun 2018 proporsi status gizi buruk dan gizi kurang pada balita $17,7 \%$, sedangkan proporsi status gizi sangat pendek dan pendek pada balita 30,8\%. Pravelensi penyakit menular seperti ISPA 4,4\% ( Riset Kesehatan Dasar, 2018). Prevalensi kejadian ISPA pada balita di Indonesia diperkirakan 3 sampai 6 kali pertahun, yang berarti seorang balita rata-rata mendapatkan serangan ISPA sebanyak 3 sampai 6 kali pertahun, dimana angka prevalensi kejadian ISPA di Indonesia 25,5\% (Riset Kesehatan Dasar, 2018).

Stunting pada anak mengakibatkan penurunan sistem imunitas tubuh dan meningkatkan resiko terkena penyakit infeksi (Lestari, Margawati and Rahfiludin, 2014). Begitu juga dengan balita stunting saat mengalami sakit batuk, pilek, demam, hingga muntah dapat berlangsung hingga 14 hari dan kronis lebih dari 14 hari (Garz and Pereira-da-silva, 2018) menyebabkan gizi anak tidak terpenuhi, kejadian tersebut dapat berulang lebih dari $6 \mathrm{x}$ per tahun (Arasj, 2015).

Peran perawat dalam mengatasi masalah ini adalah sebagai Health Educator kepada para Ibu di Posyandu balita dalam mencegah faktor resiko yang menyebabkan stunting pada anak. Apabila anak mengalami diare dengan waktu yang lama dan sering, begitu juga dengan batuk, pilek, sesak nafas disertai demam >14 hari maka lakukan pemeriksaan dini. Berdasarkan hal tersebut, peneliti ingin mengetahui hubungan kejadian stunting dengan frekuensi dan durasi penyakit ISPA pada anak usia toddler di Wilayah Kerja Puskesmas Kenjeran Surabaya.

\section{METODE}

Desain yang digunakan pada penelitian ini adalah rancangan penelitian analitik korelasi dengan pendekatan crosssectional. Jumlah keseluruhan populasi 720 anak toddler dan jumlah sampel ada 152 responden. Variabel bebas pada penelitian ini adalah Kejadian Stunting pada Anak Usia Toddler di Wilayah Kerja Puskesmas Kenjeran Surabaya dan variabel terikat pada penelitian ini adalah Frekuensi dan Durasi Penyakit ISPA pada Anak Usia Toddler di Wilayah Kerja Puskesmas Kenjeran Surabaya. Varibel Independen di ukur dengan menggunakan alat untuk mengukur balita yaitu alat pengukur badan (Microtoise) dan usia balita. Hasil tinggi badan balita akan dicocokkan menggunakan table baku z-score WHO, menurut Kementrian RI 2011 kode varibel $\mathrm{TB} / \mathrm{U}$ menggunakan penilaian sebagai berikut:

Tabel 1. Kategori dan Ambang Batas Status Gizi Anak Berdasarkan Indeks

\begin{tabular}{lll}
\hline \multicolumn{1}{c}{ Indeks } & \multicolumn{1}{c}{ Kategori Status Gizi } & \multicolumn{1}{c}{ Ambang Batas $(Z-S c o r e)$} \\
\hline \multirow{2}{*}{$\begin{array}{c}\text { Tinggi badan menurut Umur } \\
\text { (TB/U) anak usia 1- 3 tahun }\end{array}$} & Sangat Pendek & $<-3$ SD \\
\cline { 2 - 3 } & Pendek & -3 SD s/d < -2SD \\
\cline { 2 - 3 } & Normal & -2 SD s/d 2SD \\
\hline
\end{tabular}

Variabel dependen diukur menggunakan lembar kuesioner. Variabel dependennya adalah frekuensi dan durasi penyakit ISPA pada anak usia toddler di Wilayah Kerja Puskesmas Kenjeran Surabaya. Penelitian ini dilaksanakan pada 
tanggal 22 April- 22 Mei 2019 di Wilayah Kerja Puskesmas Kenjeran Surabaya. Teknik sampling dalam penelitian ini adalah Probability Sampling dengan menggunakan Stratified Random Sampling. Puskesmas Kenjeran terbagi menjadi empat wilayah/strata, wilayah kelurahan Kenjeran, kelurahan Bulak, kelurahan Kedung Cowek dan kelurahan Sukolilo. Masing-masing strata yang dipilih sebagai sampel dapat mewakili populasi dari setiap variabel.

\section{HASIL DAN PEMBAHASAN HASIL PENELITIAN}

Data umum adalah penelitian ini karakteristik responden yang meliputi jenis kelamin anak toddler yang tinggal bersama orang tua, usia anak, pendidikan ibu, pekerjaan ibu, masih diberikan ASI, pemberian ASI, pemberian MP-ASI. Sedangkan data khusus meliputi kejadian stunting dan frekuensi dan durasi penyakit infeksi ISPA.

Tabel 2: Data Umum Hubungan Kejadian Stunting dengan Frekuensi dan Durasi Penyakit ISPA pada Anak Usia Toddler Di Wilayah Kerja Puskesmas Kenjeran Surabaya.

\begin{tabular}{clccc}
\hline \multicolumn{2}{c}{ Data Umum } & $\mathrm{n}$ & Frekuensi (f) & Prosentasi (\%) \\
\hline \multirow{2}{*}{ Jenis kelamin } & Laki-Laki & \multirow{2}{*}{152} & 79 & 52.0 \\
& Perempuan & & 73 & 48.0 \\
\hline \multirow{2}{*}{ Usia Anak } & 12-23 bulan & \multirow{2}{*}{152} & 60 & 39.5 \\
& 24-36 bulan & & 92 & 60.5 \\
\hline \multirow{3}{*}{ Pendidikan } & SMA Sederajat & & 69 & 45.4 \\
Ibu & SMP Sederajat & \multirow{2}{*}{152} & 44 & 28.9 \\
& SD Sederajat & & 30 & 19.7 \\
& Perguruan Tinggi & & 9 & 5.9 \\
\hline & Ibu Rumah & & 113 & 74.3 \\
Pekerjaan & Tangga & & & 21.1 \\
Ibu & Pegawai Swasta & \multirow{2}{*}{152} & 32 & 3.3 \\
& Wiraswasta & & & 1.3 \\
\hline Masih & Pegawai Negeri & & 5 & 27.0 \\
diberikan & Tidak & & 2 & 73.0 \\
ASI & & 152 & 111 & \\
\hline Riwayat & Eksklusif & & 63 & 31.5 \\
Pemberian & Parsial & \multirow{2}{*}{152} & 54 & 23.0 \\
ASI & Predominan & & 35 & 51.4 \\
\hline \multirow{2}{*}{ Riwayat } & Bubur & & 78 & 32.2 \\
Pemberian & Susu Formula & \multirow{2}{*}{152} & 49 & 13.8 \\
MP-ASI & Sari Buah & & 21 & 2.6 \\
& Cerelac & & 4 & \\
\hline
\end{tabular}

Sumber : Data Primer, 2019

Tabel 3 : Data Khusus Hubungan Kejadian Stunting dengan Frekuensi dan Durasi Penyakit ISPA pada Anak Usia Toddler Di Wilayah Kerja Puskesmas Kenjeran Surabaya. 


\begin{tabular}{|c|c|c|c|c|}
\hline \multicolumn{2}{|c|}{ Data Khusus } & $\mathrm{n}$ & $\mathrm{f}$ & $\%$ \\
\hline \multirow{3}{*}{$\begin{array}{l}\text { Kejadian } \\
\text { Stunting }\end{array}$} & Normal & \multirow{3}{*}{152} & 76 & 50.0 \\
\hline & Pendek & & 44 & 28.9 \\
\hline & Sangat Pendek & & 32 & 21.1 \\
\hline \multirow{3}{*}{$\begin{array}{l}\text { Frekuensi } \\
\text { ISPA kurang } \\
\text { dari } 6 \text { bulan }\end{array}$} & Sering & \multirow{3}{*}{152} & 39 & 25.7 \\
\hline & Jarang & & 100 & 65.8 \\
\hline & Tidak Pernah & & 13 & 8.6 \\
\hline \multirow{3}{*}{$\begin{array}{l}\text { Durasi ISPA } \\
\text { kurang dari } 6 \\
\text { bulan }\end{array}$} & Lama & \multirow{3}{*}{152} & 68 & 44.7 \\
\hline & Tidak lama & & 70 & 46.1 \\
\hline & Tidak Pernah & & 14 & 9.2 \\
\hline
\end{tabular}

Sumber : Data Primer, 2019

Tabel 3 memperlihatkan bahwa anak toddler di wilayah kerja Puskesmas Kenjeran Surabaya sebagian besar mengalami frekuensi ISPA jarang

sebanyak 100 anak (65.8\%), anak toddler yang sering hampir setengahnya 39 anak (25\%), dan sebagian kecil 13 anak $(8.6 \%)$ tidak pernah mengalami ISPA

Tabel 4: Hubungan Kejadian Stunting dengan Frekuensi dan Durasi Penyakit ISPA pada Anak Usia Toddler di Wilayah Kerja Puskesmas Kenjeran Surabaya Mei 2019.

\begin{tabular}{lcccccccc}
\hline \multirow{2}{*}{ Kejadian Stunting } & \multicolumn{8}{c}{ Frekuensi ISPA } \\
\cline { 2 - 10 } & \multicolumn{2}{c}{ Sering } & \multicolumn{1}{c}{ Jarang } & \multicolumn{2}{c}{ Tidak Pernah } & \multicolumn{2}{c}{ Total } \\
\cline { 2 - 10 } & $\mathrm{F}$ & $\%$ & $\mathrm{~F}$ & $\%$ & $\mathrm{~F}$ & $\%$ & $\mathrm{~N}$ & $\%$ \\
\hline Normal & 12 & 7.9 & 51 & 33.6 & 13 & 8.6 & 76 & 100.0 \\
\hline Pendek & 19 & 12.5 & 25 & 16.4 & 0 & 0.0 & 44 & 100.0 \\
\hline Sangat Pendek & 8 & 5.3 & 24 & 15.8 & 0 & 0.0 & 32 & 100.0 \\
\hline \multicolumn{1}{c}{ Total } & 39 & 25.7 & 100 & 65.8 & 13 & 8.6 & 152 & 100.0 \\
\hline
\end{tabular}

Nilai uji statistik Spearmen rho $\mathrm{p}=0.001(\alpha=0.05)$

Sumber : Data Primer, 2019

\begin{tabular}{lcccccccc}
\hline \multirow{2}{*}{ Kejadian Stunting } & \multicolumn{8}{c}{ Durasi ISPA } \\
\cline { 2 - 10 } & \multicolumn{2}{c}{ Lama } & \multicolumn{7}{c}{ Tidak Lama } & Tidak Pernah & \multicolumn{2}{c}{ Total } \\
\cline { 2 - 10 } & $\mathrm{f}$ & $\%$ & $\mathrm{f}$ & $\%$ & $\mathrm{f}$ & $\%$ & $\mathrm{~N}$ & $\%$ \\
\hline Normal & 23 & 15.1 & 40 & 26.3 & 13 & 8.6 & 76 & 100.0 \\
\hline Pendek & 25 & 16.4 & 18 & 11.8 & 1 & 0.7 & 44 & 100.0 \\
\hline Sangat Pendek & 20 & 13.2 & 12 & 7.9 & 0 & 0 & 32 & 100.0 \\
\hline \multicolumn{1}{c}{ Total } & 68 & 44.7 & 70 & 46.1 & 14 & 9.3 & 152 & 100.0 \\
\hline \multicolumn{8}{c}{ Nilai uji statistik Spearmen rho $\mathrm{p}=0.001(\alpha=0.05)$} \\
\hline
\end{tabular}

Sumber : Data Primer, 2019

Tabel 4 memperlihatkan bahwa anak toddler di wilayah kerja Puskesmas Kenjeran Surabaya yang mengalami durasi ISPA tidak lama hampir setengahnya 70 anak $(46.1 \%)$. Anak toddler yang lama saat mengalami ISPA $<6$ bulan terakhir hampir setengahnya 68 anak (44.7\%).

Hasil uji statistik Spearmen rho nilai kemaknaan $\mathrm{p}=0.001$ dengan taraf signifikan $0.01(\rho<0,05)$ dapat disimpulkan bahwa hasil tersebut menunjukkan terdapat hubungan kejadian stunting dengan frekuensi penyakit ISPA pada anak usia toddler di wilayah kerja Puskesmas Kenjeran Surabaya dan hasil uji statistik Spearmen rho nilai kemaknaan $\mathrm{p}=0.001$ dengan taraf signifikan $0.01(\rho<0.05)$ dapat disimpulkan bahwa hasil tersebut menunjukkan terdapat hubungan kejadian stunting dengan durasi penyakit ISPA pada 
anak usia toddler di wilayah kerja Puskesmas Kenjeran Surabaya.

\section{PEMBAHASAN}

Berdasarkan hasil data pendidikan orang tua riwayat pendidikan ibu Sekolah Menengah Pertama (SMP) yang sering mengalami ISPA sebanyak 12 orang dan yang lama saat menderita ISPA sebanyak 23 orang. Hasil wawancara dengan orang tua menyatakan bahwa Ibu tidak memiliki pengetahuan tentang cara menangani anak ISPA sehingga saat anak terkena batuk dan pilek ibu hanya menunggu hingga sembuh. Didalam penelitian di Surakarta dimana pendidikan ibu berpengaruh terhadap insidensi ISPA pada anak (Ristiyanto, 2015). Semakin rendah pendidikan orang tua derajat ISPA semakin tinggi, demikian sebaliknya semakin tinggi pendidikan orang tua semakin rendah derajat ISPA pada anak (Maramis, Ismanto and Babakal, 2013). Pengetahuan merupakan hasil tahu dan ini terjadi melalui panca indra (Listiyorini, Irdawati and Zulaicha, 2012). Pengetahuan seseorang tentang sesuatu mengandung dua aspek yaitu aspek positif dan negatif, pernyataan ini didukung oleh penelitian bahwa ada hubungan signifikan antara tingkat pengetahuan ibu dengan upaya perawatan terhadap balita ISPA (Maramis, Ismanto and Babakal, 2013).

Peneliti berasumsi bahwa ibu belum menerima informasi tentang penanganan ISPA pada anak sehingga ibu hingga saat ini saat anak menderita batuk dan pilek atau panas ibu hanya membiarkan hingga sembuh dan menganggapnya itu hal biasa dan Ibu yang rerata lulusan SMP tidak menghiraukan jika ada petugas kesehatan memberikan informasi tentang kesehatan, ibu juga tidak terlalu memperdulikan anak saat sakit ISPA.
Anak toddler yang jarang mengalami ISPA $<6$ bulan terakhir sebanyak 100 anak (65.8\%) dan tidak lama saat mengalami ISPA $<6$ bulan terakhir sebanyak 70 anak (46.1\%). Berdasarkan hasil data pemberian ASI Eksklusif anak yang jarang mengalami ISPA sebanyak 30 orang dan yang tidak lama saat menderita ISPA sebanyak 23 orang. ASI mengandung zat protektif atau kekebalan tubuh yang dibutuhkan ank dalam 6 bulan pertama yang dapat melindungi anak dari penyakit diare, ISPA dan alergi (Hersoni, 2015). Anak yang diberi ASI eksklusif akan lebih sehat dan jarang sakit dibandingkan dengan bayi yang tidak mendapat ASI eksklusif (Depkes RI, 2018). Hasil penelitian Ariefudin (2009) tentang hubungan pemberian ASI eksklusif terhadap kejadian Infeksi Saluran Pernapasan Akut di kota tegal menunjukkan ada hubungan bermakna $\mathrm{P}$ value $=0.000(\mathrm{p}<0.05)$.

Peneliti berasumsi bahwa anak yang diberikan ASI eksklusif memiliki kekebalan tubuh yang lebih dibandingkan dengan anak yang tidak mendapat ASI eksklusif selama enam bulan pertama. Masyarakat di Wilayah Kerja Puskesmas Kenjeran masih sebagian kecil yang memberikan anak ASI eksklusif dikarenakan ibu bekerja, atau mencampuri ASI dengan air putih, teh, atau susu formula ketika anak nangis yang disebabkan mereka memiliki persepsi anak masih lapar jika hanya dikasih ASI.

Berdasarkan hasil penelitian di kategorikan normal/ tidak stunting dengan frekuensi ISPA sering sebanyak 12 anak (7.9\%) dan durasi ISPA lama sebanyak 23 anak (15.1\%). Didalam penelitian (Iskandar, Tanuwijaya and Yuniarti, 2015) Jenis kelamin dan usia menjadi salah satu faktor ISPA yang terjadi pada anak. Kondisi lingkungan dapat mempengaruhi pertumbuhan 
linear selama tahun pertama kehidupan, termasuk status gizi ibu, akses ke aman air minum, kebersihan dan sanitasi (Kismul et al., 2017). Sedangkan kategori pendek dengan frekuensi ISPA sering sebanyak 19 anak (12.5\%) dan durasi ISPA lama sebanyak 25 anak (16.4\%) dan kategori sangat pendek dengan frekuensi ISPA sering sebanyak 8 anak $(5.3 \%)$ dan durasi ISPA lama sebanyak 20 anak (13.2\%). Anak yang menderita ISPA memilik risiko 5.71 kali untuk menjadi stunting (Lestari, Margawati and Rahfiludin, 2014). Faktor risiko kejadian stunting salah satunya adalah kurangnya asupan gizi dalam jangka waktu yang lama, sehingga dapat terjadi perlambatan pertumbuhan dan berpengaruh terhadap status gizi dan mudah terserang penyakit infeksi (diare dan ISPA) (Wellina, Kartasurya and Rahfilludin, 2016). Faktor dapat menyebabkan kegagalan pertumbuhan linear, termasuk infeksi dan praktik pemberian makan suboptimal (Kismul et al., 2017). Penelitian di Etiopia Selatan menyatakan bahwa penyakit diare memiliki Asosiasi signifikan dengan stunting (Batiro et al., 2017). Peneliti berasumsi bahwa anak stunting memiliki kondisi yang perlu diperhatikan khusus karena daya tahan tubuh atau kekebalan tubuh anak stunting sangat rentan untuk terpajan penyakit infeksi yang disebabkan oleh lingkungan atau gaya hidup keluarga. Gaya hidup keluarga masyarakat Kenjeran Surabaya saat ini sebagian besar sebagai nelayan sehingga anak bebas bermain dilaut dan saat hygiene tidak diperhatikan. Tatanan rumah di daerah tersebut sangatlah kurang dilihat dari kriteria rumah sehat sehingga anak mudah terserang penyakit infeksi seperti ISPA.

Kategori normal dengan frekuensi ISPA jarang sebanyak 51 anak (33.6\%) dan durasi ISPA tidak lama sebanyak 40 anak (26.3\%). Faktor yang dapat menghambat anak tidak mudah terserang penyakit ISPA merupakan pemberian ASI Eksklusif (Abbas and SriHaryati, 2011). dan tingkat pendidikan, khususnya tingkat pendidikan ibu mempengaruhi derajat kesehatan, Hal ini terkait peranannya pada pembentukan kebiasaan makan anak, karena ibulah yang mempersiapkan makanan mulai mengatur menu, berbelanja, memasak, menyiapkan makanan, dan mendistribusikan makanan (Ni'mah, Khoirun, 2015). Peneliti berasumsi anak normal memiliki frekuensi dan durasi sakit ISPA yang lebih pendek sehingga tidak sering mengalami ISPA. Faktor lain yang mempengaruhi adalah kondisi lingkungan dan perawatan yang baik yang diberikan orang tua kepada anak sedangkan kategori pendek dengan frekuensi ISPA jarang sebanyak 25 anak (16.4\%) dan durasi ISPA tidak lama sebanyak 12 anak (7.9\%) dan kategori sangat pendek dengan frekuensi ISPA jarang sebanyak 24 anak (15.8\%) dan durasi ISPA tidak lama sebanyak 12 anak (7.9\%). Hal ini terjadi karena anak stunting tingkat kesehatan dalam wilayah tersebut tergolong rendah (Nasikhah, 2012). Peneliti berasumsi anak stunting lebih sering dan lebih lama saat menderita ISPA diakibatkan karena tingkat kesehatan yang didapatkan tidak seimbang dengan yang dibutuhkan.

Kategori normal dengan frekuensi dan durasi ISPA tidak pernah sebanyak 13 anak (8.6\%). Hal ini terjadi karena anak yang tidak stunting sudah mendapatkan perawatan kesehatan yang baik meliputi pemberian makanan yang cukup bergizi, memperhatikan tanda dan gejala ISPA (Maramis, Ismanto and Babakal, 2013). Peneliti berasumsi bahwa anak yang memiliki ibu 
berpendidikan minimal SMA menghasilkan anak yang tidak mudah terkena penyakit infeksi seperti diare disebabkan ibu mampu mengolah makanan yang tepat untuk kebutuhan anak, dan mudah menyerap dan mempraktikkan informasi tentang penanganan diare. sedangkan kategori pendek dengan durasi ISPA tidak pernah sebanyak 1 anak $(0.7 \%)$. Keluarga anak stunting belum mampu mengendalikan penyakit infeksi sehingga anak sering terkena diare dan ISPA ditambah dengan makanan yang diberikan ibu tidak berkualitas, dan masalah lingkungan (Kusumawati et al., 2013).

Peneliti berasumsi bahwa ISPA di masyarakat wilayah kerja Puskesmas Kenjeran dianggap sakit biasa yang bisa sembuh dengan sendirinya tanpa dibawa ke pelayanan kesehatan, hal itu disebabkan karena kurang pengetahuannya ibu terhadap penyakit ISPA. Hampir setengahnya ibu memiliki pendidikan SMA tetapi ibu lebih mementingkan pekerjaannya dibandingkan dengan mengurus anaknya atau anak dititipkan ke nenek dan asisten rumah tangga sehingga anak tidak mendapat perhatian khusus saat sakit batuk atau pilek.

\section{KESIMPULAN}

Penelitian ini menyatakan bahwa Anak toddler di Wilayah Kerja Puskesmas Kenjeran Surabaya sebagian besar menderita ISPA dengan frekuensi yang sering dan durasi yang lama (Berdasarkan hasil uji statistic Spearmen rho nilai kemaknaan $\mathrm{p}=$ 0.005 dengan taraf signifikan 0.01 $(\rho<0.05))$ dan durasi yang lama (Berdasarkan hasil Uji Spearmen Rho menunjukkan adanya hubungan kejadian stunting dengan frekuensi ISPA $p=0.001 \quad(p=0.05)$, durasi ISPA $p=0.001 \quad(\rho=0.05)$. Kejadian stunting memiliki hubungan signifikan dengan frekuensi dan durasi penyakit ISPA pada anak toddler di Wilayah kerja Puskesmas Kenjeran Surabaya.

\section{SARAN}

Berdasarkan hasil temuan penelitian, beberapa saran yang disampaikan pada pihak terkait adalah sebagai berikut :

1. Bagi Keluarga Balita

Penelitian ini disarankan untuk meningkatkan kewaspadaan orang tua terhadap penyakit ISPA pada anak toddler yang mengalami stunting.

2. Bagi Profesi Keperawatan

Penelitian ini disarankan untuk meningkatkan dan memperluas wawasan, dan memberikan sumbangan ilmiyah dalam keperawatan anak atau akademik gizi. Khususnya tentang kejadian stunting dengan penyakit infeksi (ISPA) pada anak toddler di Wilayah Kerja Puskesmas Kenjeran Surabaya.

3. Bagi Lahan Penelitian

Penelitian ini disarankan untuk meningkatkan kegiatan posyandu, dan penyuluhanpenyuluhan tentang kesehatan anak terutama penanganan pertama penyakit ISPA pada anak toddler.

\section{DAFTAR PUSTAKA}

Abbas, P. And Sriharyati, A. (2011) 'Hubungan Pemberian Asi Eksklusif Dengan Infeksi Saluran Pernapasan Akut (Ispa) Pada Bayi'.

Alberto, M. Et Al. (2016) 'Association Of Diarrhoea And Upper Respiratory Infections With Weight ...'

Anshori, H. Al (2013) 'Faktor Risiko Kejadian Stunting Pada Anak 
Usia 12-24 Bulan (Studi Di Kecamatan Semarang Timur)', Pp. 1-24.

Arasj, F. (2015) 'Pengaruh Pemberian Dadih ( Susu Kerbau Terfermentasi ) Melalui Makanan Tambahan Terhadap Status Gizi , Kejadian Diare Dan Ispa Anak Pendek ( Stunted ) Usia 1-4', I(I).

Batiro, B. Et Al. (2017) 'Determinants

Of Stunting Among Children Aged 6-59 Months At Kindo Didaye Woreda, Wolaita Zone, Southern Ethiopia: Unmatched Case Control Study', Pp. 1-16. Doi:

10.1371/Journal.Pone.0189106.

Fatmawati, T. Y. (2018) 'Analisis

Karakteristik Ibu , Pengetahuan

Dan Kebiasaan Merokok Dengan

Kejadian Ispa Pada Balita Di

Kelurahan Kenali Asam Bawah', 18(3), Pp. 497-502.

Garz, M. And Pereira-Da-Silva, L. (2018) 'Subclinical Enteric Parasitic Infections And Growth Faltering In Infants In S Ã O Tom É, Africa : A Birth Cohort Study', (Lmic), Pp. 1-17. Doi: 10.3390/Ijerph15040688.

Hersoni, S. (2015) 'Jurnal Kesehatan

Bakti Tunas Husada Volume 14 Nomor 1 Agustus 2015', 14, Pp. 3-9.

Iskandar, A., Tanuwijaya, S. And Yuniarti, L. (2015) 'Hubungan Jenis Kelamin Dan Usia Anak Satu Tahun Sampai Lima Tahun Dengan Kejadian Infeksi Saluran Pernapasan Akut (Ispa)', Global Medical \& Health Communication 3 (1). 1-6.

Kementrian Kesehatan Ri (No Date) 'Rencana Strategis Kementerian Kesehatan 2015-2019'.

Kesehatan, K. (2018) 'Hasil Utama Riskesdas 2018'.

Kismul, H. Et Al. (2017) 'Determinants
Of Childhood Stunting In The Democratic Republic Of Congo: Further Analysis Of Demographic And Health Survey 2013-14', Bmc Public Health. Bmc Public Health, 18(1), Pp. 1-15. Doi: 10.1186/S12889-017-4621-0.

Kusumawati, E. Et Al. (2013) 'Model Of Stunting Risk Factor Control Among Children Under Three Years', Pp. 249-256.

Lestari, W., Margawati, A. And Rahfiludin, M. Z. (2014) 'Faktor Risiko Stunting Pada Anak Umur 6-24 Bulan Di Kecamatan Penanggalan Kota Subulussalam Provinsi Aceh', 3(1), Pp. 37-45.

Listiyorini, W., Irdawati And Zulaicha, E. (2012) 'Hubungan Antara Kebiasaan Mencuci Tangan Anak Pra Sekolah Dengan Kejadian Diare Di Wilayah Kerja Puskesmas Pajang Surakarta'.

Maramis, P. A., Ismanto, A. Y. And Babakal, A. (2013) 'Hubungan Tingkat Pendidikan Dan Pengetahuan Ibu Tentang Ispa Dengan Kemampuan Ibu Merawat Balita Ispa Pada Balita Di Puskesmas Bahu Kota Manado', 1.

Nasikhah, R. (2012) 'Faktor Risiko Kejadian Stunting Pada Balita Usia 24 - 36 Bulan Di Kecamatan Semarang Timur'.

Ni'mah, Khoirun, S. R. N. (2015) 'Faktor Yang Berhubungan Dengan Kejadian Stunting Pada Balita', Media Gizi Indonesia, 1(2), Pp. 13-19. Doi: 10.1109/Inpac.2014.6981136.

Ristiyanto, R. (2015) 'Hubungan Antara Tingkat Pendidikan Formal Dan Pengetahuan Orang Tua Tentang Ispa Pada Balita Di Puskesmas Gatak'.

States, M. (2012) 'Stunting Policy Brief', (9). 
Wellina, W. F., Kartasurya, M. I. And Rahfilludin, M. Z. (2016) 'Faktor Risiko Stunting Pada Anak Umur 12-24 Bulan', 5(1), Pp. 55-61.

Who And Crissel, E. B. M. (2018) 'Level And Trends In Child Malnutrition'. 
Jurnal Ilmiah Keperawatan (Scientific Journal of Nursing), Vol 6, No 2, Tahun 2020 